\title{
DEMOCRACIA PARTICIPATIVA NA ADMINISTRAÇÃO PÚBLICA E A IMPORTÂNCIA DO PRINCÍPIO DA PUBLICIDADE
}

\section{RESUMO}

O presente trabalho tem por objetivo analisar a forma de gestão pública denominada Democracia Participativa, na qual o poder público procura engendrar mecanismos que possibilitem a participação efetiva dos cidadãos nas decisões que afetam diretamente a vida da Administração Pública. Esta forma de gestão possui

\footnotetext{
${ }^{1}$ Graduado em Direito pela Universidade Estadual de Maringá. Pós Graduado em Direito Contemporâneo com ênfase em Direito Público pela Universidade Cândido Mendes e Pós Graduado em Direito Administrativo pela Universidade Anhanguera. Analista Judiciário do Tribunal de Justiça do Estado do Paraná. Emal: hugoparana@gmail.com

${ }^{2}$ Doutor em Direito Politico e Ecônomico pela Universidade Presbiteriana Mackenzie. Professor Adjunto da Universidade do Estado de Minas Gerais - UEMG. Email: Benfatti@ hotmail.com
} 
fundamento no texto Constitucional e se materializa em institutos já previstos na legislação nacional, com destaque para o orçamento participativo, consulta popular, audiência pública, conselhos/comissões/comitês civis e as ouvidorias públicas. Contudo, para que tais mecanismos de participação popular sejam eficientes e alcancem sua finalidade, verificou-se ser essencial que a Administração observe o Princípio Constitucional da Publicidade ao disponibilizar à sociedade, de forma fácil e em tempo real, as informações necessárias à tomada de decisões, concluindo-se que isso só é possível por meio do uso de instrumentos tecnológicos e da rede mundial de computadores. As análises foram realizadas à luz da legislação em vigor e da doutrina jurídica nacional para melhor compreensão dos institutos. Concluiu-se que tais mecanismos de participação popular, se bem empregados, possibilitam que a tomada de decisões pela Administração Pública atenda aos interesses dos administrados, visto que os métodos atuais de representatividade não têm atendido esta demanda de maneira satisfatória. Portanto, evidencia-se como nunca a necessidade de a Administração Pública se apropriar das modernas práticas tecnológicas, incorporando este novo e sofisticado aspecto do Princípio Constitucional da Publicidade, a fim de que o povo possa, pelo mesmo viés da tecnologia, exercer seu poder constitucional também por meio de uma participação direta nas decisões da Administração.

Palavras-chave: Democracia participativa, Publicidade, Administração Pública.

\section{INTRODUÇÃO}

Focado na forma de gestão pública denominada Democracia Participativa e procurando defender a importância do Princípio da Publicidade para que os cidadãos possuam substrato na tomada de decisões, o que se daria pelo uso de instrumentos tecnológicos à disposição, será inicialmente analisado o conceito clássico de Estado e o motivo da adoção de uma democracia representativa. Verificar-se-á que teorias como a da representatividade e do "bem-estar social" não conseguem suprir os anseios da atual sociedade, visto que muitas atitudes dos representantes acabaram por entrar em choque com o desejo dos representados.

Assim, diante de tal constatação, apresenta-se o conceito de Democracia Participativa como alternativa de apoio à Administração Pública, abrindo um canal de acesso direto ao cidadão para interagir e opinar sobre os rumos do Estado.

Em seguida será demonstrado que a própria Constituição Federal prevê a possibilidade de participação popular de forma direta nas decisões 
do Estado, participação esta que pode ocorrer no âmbito de qualquer dos Poderes da União.

Nesta esteira, serão conceituados os principais institutos de participação popular, ou também chamados de Democracia Participativa, previstos no ordenamento jurídico brasileiro: os conselhos civis, orçamento participativo, consultas públicas, audiências públicas e as ouvidorias públicas, analisando-se suas modalidades e alcance.

Porém, diante da extensão do assunto, fez-se necessário limitar o foco do presente estudo à análise da Participação Popular na seara da Administração Pública, tendo em vista que tal espécie de participação apresenta peculiaridades próprias, não encontradas ou verificadas em menor escala nos mecanismos de participação dos demais poderes.

Evidentemente, para o alcance deste audacioso objetivo, é de suma importância que o Princípio Constitucional da Publicidade Administrativa seja observado como mecanismo que possibilite a eficaz participação do cidadão na gestão da Administração Pública, o que somente será possível por meio da plena disponibilidade de informações públicas, tanto de ordem técnica, fiscal quanto orçamentária por meio da rede mundial de computadores, proporcionando acesso à maior parte da população ao conteúdo e fundamentos das decisões, bem como o incentivo dos cidadãos ao envolvimento e utilização dos dados.

Finalmente, foram considerados os riscos desta modalidade de participação, que uma vez suprimidos, possibilitará o desenvolvimento de uma democracia sadia em nosso País e atenderá de forma satisfatória aos anseios da população.

\section{A DEMOCRACIA PARTICIPATIVA}

O estudo da Democracia Participativa no Brasil é relativamente novo e acompanha o desenvolvimento do Estado Democrático de Direito desenhado pela Carta Constitucional de 1988, assim, deve-se ter em mente que a participação popular, enquanto atividade eminentemente política do cidadão, é um dos pressupostos do Estado Democrático ${ }^{3}$.

Quando analisado de forma histórica, o que consideramos hoje como Estado Democrático teve origem na Grécia antiga, mas desenvolveu-

\footnotetext{
${ }^{3}$ DALLARI. Dalmo de Abreu. O que é Participação Política. São Paulo: Brasiliense, 1985.
} 
se de maneira intensa a partir da Revolução Francesa ${ }^{4}$ que tornou clássica a divisão dos poderes estatais, além de ressaltar o respeito à legalidade, o reconhecimento de direitos e garantias fundamentais como a cidadania, e a realização periódica de eleições que legitimariam os governos. Tal ideia materializou-se na célebre frase do estadista norte americano Abraham Lincoln: um "governo do povo, pelo povo e para o povo" 5

Neste momento, formatou-se o conceito clássico de democracia, que inegavelmente se submetia à realidade histórica das limitações geográficas e deficiência no acesso às informações públicas pela população, tornando necessária a utilização do sistema representativo para que o cidadão possuísse voz, sistema este elevado à norma jurídica pela Constituição Alemã de Weimar de 1919. Assim, elegendo de tempos em tempos seus governantes e legisladores, o povo estaria autorizando que tais pessoas decidissem os rumos da nação e havendo divergências entre o governante e o senso da maioria, a única forma de manifestar-se seria eleger outro indivíduo que melhor a representasse.

Paralelamente ao conceito de Estado Democrático desenvolvido após a Revolução Francesa, construiu-se a ideia do "estado de bem-estar", o qual "não se limita a manter a ordem pública, mas desenvolve inúmeras atividades na área da saúde, educação, assistência, previdência social e cultura, sempre com o objetivo de promover o bem-estar coletivo"6, que, na prática, resultou na criação de inúmeros direitos aos cidadãos diante do Estado.

Ademais, no que diz reseito à organização da Administração estatal, desenvolveram-se os conceitos de burocracia e racionalidade de Max Weber, sistematizados em resumo como sendo "uma Administração Pública organizada racionalmente, cujo funcionamento fosse tão previsível e regular quanto o funcionamento de uma máquina, baseado em princípios e normas gerais fixos". ${ }^{7}$

A burocracia aliada à eficiência e legitimidade representam verdadeiros pilares de sustentação da Administração Pública sob a égide do modelo weberiano, proporcionando autonomia da Administração em

\footnotetext{
${ }^{4}$ MIRANDA, J. Manual de direito constitucional: preliminares, o Estado e os sistemas constitucionais. $6^{\text {a }}$ ed. Coimbra: Coimbra Editora, 1997.

${ }^{5}$ LINCOLN. Abraham. Great Speeches. Nova York: Dover, 1991.

${ }^{6}$ DI PIETRO, Maria Sylvia Zanella. Direito Administrativo. São Paulo: Atlas. 2011.

${ }^{7}$ PEREZ, Marcos Augusto. op. cit., p. 46.
} 
relação à sociedade ao distanciá-la dos conflitos sociais e políticos, proporcionando, assim, uma gestão técnica e profissional dos serviços públicos. ${ }^{8}$

Todavia, a implementação do Estado democrático voltado ao bem-estar social e fundamentado na autonomia da Administração Pública em relação à sociedade não resultou, na prática, em uma vantagem para a sociedade, vez que a história mostrou que os Estados se tornaram "fortes para reprimir a sociedade civil, mas até certo ponto fracos para implementar políticas públicas realmente hegemônicas", como ocorre no Estado Brasileiro.

Além do distanciamento prático do que é esperado pelo Estado e do que ele tem realmente feito, vê-se que os representantes eleitos pelo povo têm, por vezes, dificuldade em representá-lo efetivamente, pois os indivíduos, uma vez eleitos, passaram a se "profissionalizar" na política, se interessando pelo cidadão apenas nos períodos eleitorais. Além disso, os representantes não se mostram capazes de identificar e resolver os reais problemas sociais ou estabelecer um contato, um diálogo com seus eleitores, resultando num afastamento e desinteresse dos cidadãos pela participação política. Auxiliando negativamente esta realidade, sucessivos escândalos envolvendo desvio de verbas públicas, abuso da máquina estatal, concentração de poderes no Executivo e manipulação de informações pelos meios de comunicação fazem com que o sistema representativo se apresente desgastado, não alcançando seu objetivo para com os representados.

Diante deste contexto, a Democracia Participativa surge como uma alternativa aos problemas enfrentados pela democracia representativa, tendo como objetivo reforçar os controles sobre a atuação estatal ${ }^{10}$, pois se constitui na abertura do Estado para uma maior participação do cidadão nos rumos da atividade pública do que o admitido pelo sistema representativo.

Sua fundamentação se encontra disposta no artigo $1^{\circ}$ da Constituição Federal no qual é previsto que "Todo o poder emana do povo, que o exerce por meio de representantes eleitos ou diretamente" 11 . Analisando o tema, o mestre constitucionalista José Afonso da Silva ensina que a

\footnotetext{
${ }^{8}$ PEREZ, Marcos Augusto. op. cit., p. 46.

${ }^{9}$ FARIA, José Eduardo. A crise constitucional e a restauração da legitimidade. Porto Alegre: Fabris, 1985.

${ }^{10}$ BOBBIO, Norberto. A era dos Direitos. Rio de Janeiro: Campus, 1992.

${ }^{11}$ BRASIL. Constituição (1988). Constituição da República Federativa do Brasil. Brasília, DF: Senado Federal: Centro Gráfico, 1988.
} 
Democracia é "participativa porque envolve a participação crescente do povo no processo decisório e na formação dos atos de governo; pluralista, porque respeita a pluralidade de ideias, culturas e etnias e pressupõe assim o diálogo entre opiniões e pensamentos divergentes da sociedade.". ${ }^{12}$

Portanto, é possível afirmar que a participação popular na Administração Pública representa uma superação do modelo weberiano ao reaproximar do Estado a opinião social, a fim de que os problemas sociais sejam resolvidos de forma eficiente, transparente e com uma responsabilidade compartilhada; bem como minimizar as mazelas do clássico sistema democrático de representação, dando voz ao cidadão e permitindo que ele fiscalize o poder público.

Para Sylvia Zanella Di Pietro ${ }^{13}$, na presente fase do desenvolvimento democrático a participação do particular na gestão pública se dá mediante sua atuação direta no controle da Administração, tornando-se uma característica essencial do Estado de Direito Democrático, porque aproxima mais o administrado da Administração, diminuindo as barreiras entre o Estado e a denominada "sociedade da informação" 14 .

Ensina o professor do Largo São Francisco, Marcos Augusto Perez, que nos Estados de Direito contemporâneos a participação do cidadão no desempenho das funções estatais é uma constante, tanto em aspiração como em realidade, complementando a atuação do poder público ${ }^{15}$ também na seara Administrativa.

Neste sentido, o mesmo autor destaca dois benefícios da democracia participativa, sendo o primeiro a aproximação da sociedade ao Estado, fazendo com que ele se abra para a busca de suas finalidades

12 SILVA, José Afonso da. Curso de Direito Constitucional Positivo. São Paulo: Revista dos Tribunais. 2000.

${ }^{13}$ DI PIETRO, Maria Sylvia Zanella, op. cit.

${ }^{14} \mathrm{O}$ conceito de sociedade da informação pode ser encontrado na obra de Manuel Castells e diz respeito à revolução tecnológica que deu origem ao denominado informacionalismo, tornando-se assim a base material dessa nova sociedade, onde os valores da liberdade individual e da comunicação aberta tornaram-se supremos. Nesse contexto, "as tecnologias assumem um papel de destaque em todos os segmentos sociais, permitindo o entendimento da nova estrutura social - sociedade em rede - e consequentemente, de uma nova economia, na qual a tecnologia da informação é considerada uma ferramenta indispensável na manipulação da informação e construção do conhecimento pelos indivíduos, pois a geração, processamento e transmissão de informação torna-se a principal fonte de produtividade e poder”. Em, CASTELLS, Manuel. A Era da Informação: economia, sociedade e cultura, vol. 3. São Paulo: Paz e terra, 1999.

15 PEREZ, Marcos Augusto. op. cit., p. 62. 
primordiais, como a efetividade dos direitos humanos por meio da legalidade e o bem-estar dos cidadãos, proporcionando o desenvolvimento econômico e social da nação.

O segundo ponto destacado reside no fato de que a participação popular gera "maior legitimação do Estado e do Direito", aproximando o cidadão tanto da gestão, quanto das suas responsabilidades e consequências, possibilitando o controle da Administração Pública pela coletividade.

\section{FUNDAMENTOS CONSTITUCIONAIS}

Uma vez identificados os fundamentos políticos e sociais que convergem na necessidade de maior participação popular na vida do Estado, é possível afirmar que a Constituição da República Federativa do Brasil promulgada em 1988 traz, em seu bojo, previsão expressa quanto ao exercício de uma democracia participativa. Esta constatação é de alta relevância, pois legitima a existência de institutos próprios de participação popular na Administração Pública.

A participação popular possui fundamento primordial no Princípio da Soberania Popular previsto no art. $1^{\circ}$ da Constituição Federal, sendo permitido ao povo exercer seu poder diretamente, ou seja, “da conjugação da Democracia representativa e Democracia direta temos um modelo misto de Democracia semidireta, que nada mais é senão uma Democracia representativa com alguns institutos ou mecanismos de participação direta do povo na formação da vontade política nacional. Da Democracia semidireta se desenvolve a chamada Democracia Participativa." 16

Analisando o texto constitucional, é possível afirmar que há autorização para a participação popular no exercício de todas as funções estatais e, como exemplo, pode-se citar o plebiscito e o referendo previstos no art. 14, incisos I e II, e a iniciativa popular do processo legislativo prevista no art. 61 , caput e $\S 2^{\circ}$, que são institutos de participação direta do cidadão na função legislativa.

No exercício da função jurisdicional, a constituição prevê inúmeros institutos de participação popular, podendo ser citado como exemplo o Júri popular (art. $5^{\circ}$, inc. XXXVI), a ação popular (art. $5^{\circ}$, inc. LXXIII),

\footnotetext{
${ }^{16}$ CUNHA JUNIOR, Direley da. Curso de Direito Constitucional. $7^{\mathrm{a}}$.ed., Salvador: Editora Juspodivm, 2013.
} 
ação civil pública e o mandado de segurança individual e coletivo (art. $5^{\circ}$, inc. LXIX e LXX), sempre pressupondo a defesa do interesse público.

No âmbito da função executiva/administrativa, destaca-se a atuação popular na Administração Pública através de institutos como o direito de petição (art. $5^{\circ}$, inc. XXXIV), e os inúmeros conselhos consultivos no âmbito da saúde (art. 198, inc. III) e cultura (art. 216, § $1^{\circ}$ ).

Portanto, a implementação de institutos de participação popular na Administração Pública possui forte fundamento no texto constitucional e reflete de forma clara o objetivo do constituinte originário em estimular o envolvimento dos cidadãos na condução do Estado.

\section{DOS INSTITUTOS DE PARTICIPAÇÃO POPULAR}

Antes da análise específica dos institutos de participação popular previstos no ordenamento jurídico brasileiro, necessário lembrar que apesar de a própria Constituição Federal prever a participação popular em todas as funções estatais, o objeto do presente estudo é a análise da Democracia Participativa aplicada à função executiva/administrativa e seus institutos específicos, assim, não serão tratados institutos afetos às funções legislativa e jurisdicional.

Isto posto, ainda que não haja um consenso na conceituação da expressão "institutos de participação popular na Administração Pública", tendo em vista a complexidade das relações que envolvem seu estudo, mostra-se de grande valia o ensino de Marcos Augusto Perez, para quem eles são "instrumentos legalmente previstos que possibilitam aos administrados, diretamente ou através de representantes escolhidos especificamente para este fim, tomar parte na deliberação, na execução ou no controle das atividades desenvolvidas pela Administração Pública"17 . Tais instrumentos teriam como principal objetivo aprimorar a eficiência da atuação administrativa e dar efetividade aos direitos fundamentais por meio da colaboração entre a sociedade e a Administração, da busca da adesão, do consentimento e do consenso dos administrados e, afinal, da abertura e transparência dos processos decisórios.

Uma vez apresentado o conceito, resta importante trazer a lume critérios que diferenciem entre si os institutos e permitam a identificação

${ }^{17}$ PEREZ, Marcos Augusto. op. cit., p. 96. 
da natureza jurídica de cada um, bem como seu modo de funcionamento. Para tanto, e devido à brevidade do presente trabalho, será adotada classificação proposta pelo consagrado constitucionalista português J.J. Canotilho ao tratar do Princípio da Participação Popular em sua obra de Direito Constitucional. Para ele existem três espécies de participação pública nos processos decisórios: participação não-vinculante, participação vinculante e a participação vinculante e autônoma ${ }^{18}$.

A participação não-vinculante consiste na participação popular nos processos de decisão "apenas através de informações, propostas, exposições e protestos". Por sua vez, a participação vinculante "significa participação na própria tomada de decisão e, consequentemente, limitação do poder de direcção tradicional (participação, por ex., em conselhos de gestão)"; e por fim, a participação vinculante e autônoma (autogestão) ocorre "quando se trata de uma substituição pura e simples do poder de direção da Administração". ${ }^{19}$

Convertendo a classificação do ilustre professor aos institutos existentes no ordenamento jurídico brasileiro, é possível verificar que há adequação conceitual para ordená-los, levando em conta os exemplos da consulta pública - instituto não vinculante; dos conselhos deliberativos instituto vinculante; e as organizações sociais - institutos vinculantes e autônomos. ${ }^{20}$

Neste momento, cabe ainda realizar mais uma observação de ordem estrutural: o autor argentino Gordillo, de forma objetiva, classifica os mesmos institutos de participação popular em apenas dois tipos, quais sejam, "técnicas consultivas" e "gestão participativa" 21 . A esta classificação poderemos adequar o que foi dito por Canotilho da seguinte forma: participação não vinculante e vinculante como sendo técnicas consultivas, e a participação vinculante e autônoma como a técnica da gestão participativa.

A importância desta divisão reside no fato de que a finalidade do presente trabalho é destacar a importância do Princípio da Publicidade no contexto de uma participação popular ativa, e tal objetivo parece possuir

\footnotetext{
${ }^{18}$ CANOTILHO, José Joaquim Gomes. Direito Constitucional. $6^{\mathrm{a}}$ ed. Coimbra: Almedina, 1993.

${ }^{19}$ Ibidem.

${ }^{20}$ PEREZ, Marcos Augusto. op. cit., p. 118.

${ }^{21}$ GORDILLO, Augustin. Tratado de Derecho Administraivo - Parte General. Buenos Aires: Machi, 1995.
} 
maior relevância sobre os institutos relacionados às técnicas consultivas (não vinculantes e vinculantes).

Esta constatação decorre do fato de que a gestão participativa, como forma de participação vinculante e autônoma, possui caráter executório, como é o caso das organizações sociais não governamentais (ONGs) e as entidades de utilidade pública, que exercem um tipo de "delegação atípica" da atividade pública ${ }^{22}$. Neste contexto, o Princípio da Publicidade não exerce a influência que se busca destacar.

Assim, focaremos no próximo item: os institutos de participação popular vinculantes e não vinculantes, de caráter consultivo e deliberativo, os quais necessitam de um arcabouço informativo garantido somente pelo Princípio da Publicidade para que seus objetivos sejam alcançados.

Ademais, em vista da competência concorrente entre União, Estados e Municípios para legislarem sobre a criação de institutos de participação popular, nos termos dos artigos $18,25, \S 1^{\circ}, 29$ e 48, IX da Constituição Federal, natural que existam inúmeros instrumentos legais com esse fim, portanto, para uma proveitosa análise do tema, merecem destaque os institutos que possuem constante referência na legislativa infraconstitucional: o orçamento participativo, a consulta popular, a audiência pública, os conselhos/comissões/comitês civis e as ouvidorias públicas.

\section{INSTITUTOS ESPECÍFICOS}

Tais institutos, como poderá ser visto pela legislação apresentada, são novidades para a Administração Pública do Brasil, pois implementados ou confirmados pela Constituição Cidadã de 1988 que trouxe em seu bojo o já estudado Princípio da Participação Popular na própria Administração, resultando em verdadeira modalidade de controle social da atuação do Poder Público.

\subsection{CONSELHOS, COMISSÕES OU COMITÊS CIVIS}

\footnotetext{
${ }^{22}$ MOREIRA NETO, Diogo e Figueiredo. Direito da Participação Política. Rio de Janeiro: Renovar, 1992 apud PEREZ, Marcos Augusto. op. cit., p. 186.
} 
É o instituto de participação popular mais comum no ordenamento jurídico brasileiro, possuindo geralmente um caráter vinculante nos termos da classificação utilizada, posto que as leis que os criam tornam as decisões colegiadas verdadeiras regras para condução do tema pelo executivo.

De maneira didática, pode-se conceituar o instituto como sendo "órgãos colegiados, ora com função deliberativa, ora com função meramente consultiva, que reúnem representantes da Administração Pública e da sociedade, com ou sem paridade de representação, e que participam do processo decisório de uma determinada área de interesses da Administração"23.

A criação destes conselhos pode ser realizada por lei ou mediante autorização legal, sem, contudo, adquirir personalidade jurídica, autonomia gerencial, administrativa ou financeira, e não contrair obrigações, adquirindo capacidade postulatória somente em casos excepcionais que envolvam o exercício de suas prerrogativas decisórias.

Sem dúvida, os conselhos civis previstos em âmbito federal, como o Conselho Nacional de Turismo - Lei 7.174/1983, Conselho Nacional dos Direitos da Mulher - Lei 7.353/1985, Conselho Nacional dos Direitos da Criança e do Adolescente - Lei 8.242/1991, Conselho Monetário Nacional - Lei 8.646/1993, dentre muitos outros existentes, garantem a participação ativa dos cidadãos por meio de representantes da sociedade civil que neles atuam, com direito a voto e resoluções que vinculam a Administração Pública.

\subsection{ORÇAMENTO PARTICIPATIVO}

Sua previsão remonta à Lei Complementar 101/2000 - Lei de Responsabilidade Fiscal - que determina no artigo 48 a realização de audiências públicas durante o processo de elaboração das leis orçamentárias, criando um novo mecanismo de participação pública, agora, na esfera da gestão financeira do ente.

Podem ser conceituados como "um procedimento administrativo que compreende a realização de diversas audiências públicas, geralmente regionalizadas, por vezes acompanhadas da eleição de representantes para

${ }^{23}$ PEREZ, Marcos Augusto. op. cit., p. 98. 
diferentes conselhos deliberativos, os quais têm o objetivo de preparar, sob a coordenação da Administração, o projeto de lei orçamentária enviado pelo Executivo ao Legislativo." 24

Considerando então que tais audiências objetivam analisar e fiscalizar o projeto de lei orçamentária, suas conclusões assumem caráter não vinculante, posto serem submetidas à análise e aprovação pelo executivo.

\subsection{CONSULTA PÚBLICA}

De forma objetiva, pode-se conceituar Consulta Pública como um procedimento de divulgação prévia de minutas de atos normativos, permitindo que, em determinado prazo, todos os eventuais interessados ofereçam críticas, sugestões de aperfeiçoamento ou peçam informações a seu respeito $^{25}$.

Apesar de naturalmente possuir caráter não vinculante, este instituto possibilita uma maior atuação do cidadão em relação à decisão do governante, posto que, apesar de a Administração Pública não ser obrigada a aceitar todas as sugestões, ela deverá motivar a decisão que contrariou as propostas documentadas na consulta, tornando, de igual modo, públicas as respostas e os motivos de sua deliberação.

Este mecanismo de participação popular foi criado pela Lei 9.472/199726 , denominada Lei Geral das Telecomunicações, que em seus artigos 19 e 42 obrigam a Agência Nacional de Telecomunicações realizar consulta pública em que serão apresentadas minutas de atos normativos de competência da Presidência da República ou de Ministro de Estado referentes à definição da política e do regime jurídico dos serviços de telecomunicações no Brasil, sendo que as críticas e sugestões serão relatadas à autoridade; daí em diante, tornou-se muito utilizada pela Administração na busca pela participação popular em matéria de interesse geral, antes da tomada de decisão.

\footnotetext{
${ }^{24}$ PEREZ, Marcos Augusto. op. cit., pág. 108.

${ }^{25}$ Ibidem, pág. 108

${ }^{26}$ MODESTO, Paulo. Participação popular na Administração Pública: mecanismos de operacionzalização. Salvador: Revista eletrônica de direito, $\mathrm{n}^{\circ} 2$, abril/mail/junho de 2005. Disponível em <http://www.direitodoestado.com/revista/REDE-2-ABRIL-2005PAULO\%20MODESTO.pdf >. Acessado em 23/06/2014.
} 


\subsection{AUDIÊNCIA PÚBLICA}

Outro instituto de participação popular bastante frequente no ordenamento jurídico brasileiro e que também possui caráter não vinculante é o da audiência pública, que pode ser conceituado como uma "reunião organizada pela Administração Pública em determinada fase do procedimento decisório. É uma sessão aberta a todos os interessados, onde estes exercem seu direito de requerer esclarecimentos, fazer críticas ou dar sugestões e contribuições a respeito de uma determinada decisão que será tomada pela Administração."27

Sua realização é obrigatória segundo determinados procedimentos legais, como nas Licitações com valor acima de cem vezes o valor limite previsto para a realização de concorrência pública de obras e serviços de engenharia (artigos 39 e 23 da Lei 8.666/1993) e para "análise e ampla divulgação de relatórios detalhados contendo, dentre outros, dados sobre o montante e a fonte de recursos aplicados, as auditorias concluídas ou iniciadas no período, bem como a oferta e produção de serviços (...)"28 , previstas na Lei $n^{\circ} 8.689 / 1993$, artigo 12, que dispõe sobre o Sistema único de Saúde.

Na seara municipal, tal mecanismo encontra sua aplicação mais eficiente, seja para concretização do planejamento municipal, como previsto na Lei 10.257/2001 (Estatuto das Cidades) ou nos diversos conselhos relacionados à saúde, educação e políticas municipais.

\subsection{OUVIDORIAS PÚBLICAS}

Trata-se de uma entidade criada por lei, de caráter não vinculante e ligada a determinado órgão, que será responsável por fiscalizar a atuação da Administração Pública por meio da figura do Ouvidor, que pode ser eleito ou indicado para esta determinada função de receber as reclamações e observações do cidadão ${ }^{29}$. Vários órgãos têm adotado esta prática por determinação legal, sendo possível citar como exemplos a Lei da

\footnotetext{
${ }^{27}$ PEREZ, Marcos Augusto. op. cit., pág. 105.

${ }^{28}$ BRASIL, Lei n ${ }^{\circ} 8.666$, de 21 de junho de 1993, com alterações resultantes da Lei 8.883, de 08 de junho de 1994 e da Lei 9.648, de 27 de maio de 1997. Disponível < http://www.planalto.gov.br/ccivil_03/leis/L8666cons.htm> acesso em 10/01/2017.

${ }^{29}$ Ibidem, pág. 104.
} 
Seguridade Social, Lei n ${ }^{\circ} 8.212 / 1991$, artigo 79, que institui o Ouvidor Geral da seguridade social e a Lei 8.490/1992 que cria a Ouvidoria Geral da República, dentre outras.

Estes institutos foram criados na esteira do Princípio Constitucional da Participação Popular e materializados pelas legislações federal, estaduais e municipais, e têm o nítido objetivo de estimular o cidadão a tomar parte, de forma direta ou através de representes, dos processos decisório e do controle das ações realizadas pela Administração que causam impacto no cotidiano da coletividade.

\section{PRINCÍPIO CONSTITUCIONAL DA PUBLICIDADE}

Todavia, para que o Princípio da Participação Popular na vida do Estado seja efetivado de forma qualificada pelo cidadão, e as decisões, fiscalização ou posicionamento perante a Administração Pública sejam eficientes, é necessário que todas as informações sobre o assunto em discussão sejam disponibilizadas. Este é o escopo da observância estrita ao Princípio da Publicidade Administrativa previsto no artigo 37 de nossa Constituição Federal.

Mais que o já consagrado direito do cidadão de receber dos órgãos públicos informações de seu interesse particular ou coletivo (art. $5^{\circ}$, inc. XXXIII da CF), tal Princípio obriga que a Administração Pública atue com transparência, tornando públicos todos os motivos de suas ações, valores gastos, objetivos, e adote mecanismos que tornem estas informações acessíveis a toda a população ${ }^{30}$.

Revisando este basilar Princípio Constitucional, considera-se transparência a democratização do acesso às informações, em contraposição ao sigilo das mesmas ${ }^{31}$, tornando este o maior desafio a ser superado pelo Estado atual.

Nesta esteira, não há dúvidas de que a sociedade contemporânea, ao utilizar de modo intenso a internet e as redes sociais em seu dia a dia, tem mudado radicalmente a forma de interação com seus representantes

${ }^{30}$ ATALIBA, Geraldo. República e Constituição. $2^{a}$ ed. Atual. Por Rosolea Folgosi. São Paulo: Malheiros Editores, 1998.

31 TRISTAO, Gilberto. Transparência na administração pública. VII Congreso Internacional del CLAD sobre la Reforma del Estado y de la Administración Pública, Lisboa, Portugal, 8-11 Oct. 2002. 
legais e por esta razão, a Administração Pública em todos os níveis deve se adequar a esta realidade social e procurar responder às demandas dos cidadãos que anseiam por maior participação, transparência e efetividade do Poder Público.

Sem dúvida, estas exigências são imposições da moderna sociedade da informação, composta por indivíduos que possuem grande facilidade em acessar informações por meio da rede mundial de computadores e delas fazer uso para seu convencimento. Neste sentido, o ilustre professor Kiyoshi Harada afirma que "A participação popular, sem dúvida alguma, confere maior transparência nos atos da Administração Pública que, assim, passa a revestir-se da característica de legitimidade, que antecede o plano da legalidade. Essa participação pode ocorrer através da Internet, disponibilizando as diferentes matérias objeto de consulta popular em homepages específicos." 32

Verifica-se, portanto, que uma atuação eficiente do cidadão depende da observância pela Administração Pública do Princípio da Publicidade como mecanismo essencial para a formação de opinião e tomada de decisões, o que atualmente pode ser alcançado por intermédio dos meios eletrônicos, veículo apto e capaz de proporcionar a interação e participação ativa dos cidadãos nos rumos da Administração Pública.

\section{CONCLUSÃO}

À vista do exposto, verifica-se que diante da problemática que envolve a clássica concepção de democracia representativa, a democracia participativa surge como alternativa para complementar a gestão administrativa e partilhar as responsabilidades com os cidadãos, possibilitando-lhes opinar, decidir e fiscalizar a atuação da Administração Pública.

Esta atuação é legítima e encontra amparo na própria Constituição Federal, motivo pelo qual os institutos específicos de participação popular mostram-se verdadeiras "portas de entrada" do cidadão que pretende interagir com a Administração Brasileira. Tal anseio pode ser identificado quando vemos manifestações populares de extensão nacional ocorridas nos últimos anos, que salvo ações depredativas verdadeiramente

\footnotetext{
${ }^{32}$ HARADA, Kiyoshi. Responsabilidade fiscal: lei complementar ${ }^{\circ}$ 101/2000 comentada e legislação correlata anotada. São Paulo: Editora Juarez de Oliveira, 2002.
} 
desnecessárias, parecem demonstrar em sua concepção mais íntima a vontade de certa parte da população em participar das decisões do Estado e na atuação de seus representantes.

Por outro lado, não se está propondo que o modelo representativo deva ser substituído ou que se deva adotar uma governança pelo povo, aos moldes de algumas ideologias políticas (como a soviética), mas sim, que a participação popular, principalmente na Administração Pública, pode contribuir para que o Estado atue em compasso com os interesses da nação e dos representados, em decorrência de consultas a eles realizadas ou como resultado de sua físcalização.

Neste contexto, o Estado tende a assumir um papel de mediador dos conflitos e das forças sociais diante da atual sociedade da informação, e tal situação justifica a existência de institutos de participação popular regulados pela legislação e que permitam que opiniões diversas possam ser consideradas pela Administração.

Evidente que a adoção deste modelo infere desafios e riscos, como explicitado por Perez, podendo ser citado o risco de "captura pelo governo" 33, o qual assumiria esta massa a fim de legitimar suas decisões impositivas, o que representaria uma "involução do caráter democrático e representativo". Portanto, a existência de institutos devidamente regulados em lei pode limitar e afastar tal risco.

Outro perigo é a corrupção praticada pelos governantes a fim de se aproximar de grupos sociais atendendo seus interesses em troca de apoio; daí a grande necessidade de que todos os atos da Administração sejam transparentes, o que somente pode ser alcançado com a disponibilização deles na internet, para acesso por todos os cidadãos ${ }^{34}$. Nesta esteira, pode-se ainda destacar o risco da "deficiência de análise", que pode ocorrer quando "a aproximação entre sociedade e Administração na formulação, decisão e execução de políticas públicas politize-se de modo tão extremado que retire dessas atividades todo o conteúdo técnico ou planejamento necessário a sua concretização" 35 . Neste ponto, somente a interação do cidadão com a vida pública e um arcabouço informativo claro, aliados à intolerância, à demagogia e ao populismo, poderão superar tais dificuldades, garantindo uma atuação clara e eficiente da população.

\footnotetext{
${ }^{33}$ PEREZ, Marcos Augusto. op. cit., pág. 227.

${ }^{34}$ Ibidem, pág. 229.

${ }^{35}$ Ibidem, pág. 230.
} 
De todo modo, vê-se que a Participação Popular é um princípio constitucional, e como tal, deve ser observado também pela Administração Pública na formulação de políticas que a incentivem e afastem os riscos acima analisados.

Evidencia-se ainda a necessidade de observância ao Princípio da Publicidade como pano de fundo da participação popular, pois somente com acesso às informações públicas é que o cidadão poderá atuar com qualidade; e diante do perfil da atual sociedade, é dever da Administração fazer uso dos meios eletrônicos para difundir tais informações, tornando-as acessíveis a toda a população.

\section{REFERÊNCIAS BIBLIOGRÁFICAS}

ATALIBA, Geraldo. República e Constituição. $2^{a}$ ed. Atual. Por Rosolea Folgosi. São Paulo: Malheiros Editores, 1998.

BOBBIO, Norberto. A Era dos Direitos. Tradução de Carlos Nelson Coutinho. 10. ed., Rio de Janeiro: Campus, 1992.

BONAVIDES, Paulo. Teoria Constitucional da Democracia Participativa. São Paulo: Malheiros, 2001.

BRASIL. Constituição (1988). Constituição da República Federativa do Brasil. Brasília, DF: Senado Federal: Centro Gráfico, 1988.

BRASIL, Lei $\mathrm{n}^{\circ}$ 8.666, de 21 de junho de 1993, com alterações resultantes da Lei 8.883, de 08 de junho de 1994 ne da Lei 9.648, de 27 de maio de 1997. Disponível < http://www.planalto.gov.br/ccivil_03/leis/L8666cons.htm> acesso em 10/01/2017.

CANOTILHO, José Joaquim Gomes. Direito Constitucional. Coimbra: Almedina, 1993.

CASTELLS, Manuel. A Era da Informação: economia, sociedade e cultura, vol. 3. São Paulo: Paz e terra, 1999.

, Manuel. O poder da identidade. Tradução Klauss Brandini Gerhardt. São Paulo: Paz e Terra, 2010.

A sociedade em rede. Tradução Roneide Venancio Majer e Klauss Brandini Gerhardt. São Paulo: Paz e Terra, 2012.

CHEVALLIER, Jacques. O Estado pós-moderno. Tradução de Marçal Justen Filho. Belo Horizonte: Fórum. Coleção Fórum Brasil - França de Direito Público, 2009.

CUNHA JUNIOR, Direley da. Curso de Direito Constitucional. $7^{\text {a }}$.ed., Salvador: Editora Juspodivm, 2013.

DALLARI. Dalmo de Abreu. O que é Participação Política. São Paulo: Brasiliense, 1985. 
DI PIETRO, Maria Sylvia Zanella. Direito Administrativo. São Paulo: Atlas. 2011.

FARIA, José Eduardo. A crise constitucional e a restauração da legitimidade. Porto Alegre: Fabris, 1985.

GORDILLO, Augustin. Tratado de Derecho Administraivo - Parte General. Buenos Aires: Machi, 1995.

HARADA, Kiyoshi. Responsabilidade fiscal: lei complementar no 101/2000 comentada e legislação correlata anotada. São Paulo: Editora Juarez de Oliveira, 2002.

LIMA, Edilson Vitorelli Diniz. \& TELLO, Diana Carolina Valencia. A administração pública nas sociedades da informação e do conhecimento. Revista de Direito Administrativo. Belo Horizonte, n.262, jan./abr. 2013.

LINCOLN. Abraham. Great Speeches. Nova York: Dover, 1991.

MELLO, Celso Antônio Bandeira de. Curso de Direito Administrativo. $26^{a}$ ed. São Paulo: Malheiros, 2009.

MINAS GERAIS. Plano de Governo. Minas de todos os mineiros. As redes sociais de desenvolvimento integrado. Antonio Augusto Junho Anastasia - 2011.

MIRANDA, Jorge. Manual de direito constitucional: preliminares, o Estado e os sistemas constitucionais. $6^{\text {a }}$ ed. Coimbra: Coimbra Editora, 1997.

MODESTO, Paulo. Participação popular na Administração Pública: mecanismos de operacionzalização. Salvador: Revista eletrônica de direito, $\mathrm{n}^{\circ} 2$, abril/mail/junho de 2005. Disponível em <http://www.direitodoestado.com/revista/ REDE-2-ABRIL-2005- PAULO\%20MODESTO.pdf >. Acessado em 23/06/2014.

MOREIRA NETO, Diogo e Figueiredo. Direito da Participação Política. Rio de Janeiro: Renovar, 1992.

OLIVO, Luiz Carlos Cancellier de. Desafios do Direito Administrativo diante do Estado em rede. Florianópolis: EdUFSC, 2001.

PEREZ, Marcos Augusto. A administração pública democrática: institutos de participação popular na administração pública. Belo Horizonte: Fórum, 2009.

SILVA, José Afonso da. Curso de Direito Constitucional Positivo. São Paulo: Revista dos Tribunais. 2000.

TRISTAO, Gilberto. Transparência na administração pública. VII Congreso Internacional del CLAD sobre la Reforma del Estado y de la Administración Pública, Lisboa, Portugal, 8-11 Oct. 2002. Disponível em <http://www. http://unpan1.un.org/intradoc/groups/public/documents/clad/clad0043714.pdf>. Acessado em 23/06/2014. 